\title{
Glucosylation of Rho GTPases by Clostridium difficile toxin A triggers apoptosis in intestinal epithelial cells
}

\author{
Correspondence \\ Ralf Gerhard \\ gerhard.ralf@mh-hannover.de
}

Received 16 November 2007

Accepted 2 March 2008

\author{
Ralf Gerhard, Stefanie Nottrott, Janett Schoentaube, Helma Tatge, \\ Alexandra Olling and Ingo Just
}

Institute of Toxicology, Hannover Medical School, 30625 Hannover, Germany

\section{INTRODUCTION}

Clostridium difficile is a pathogen that causes antibioticassociated diarrhoea and severe pseudomembranous colitis. Toxin $\mathrm{A}(\mathrm{Tcd} \mathrm{A})$ and toxin $\mathrm{B}(\mathrm{TcdB})$ are the main pathogenic factors released by $C$. difficile (Just \& Gerhard, 2004). The toxins are homologous glucosyltransferases that mono-glucosylate Rho GTPases (Rho, Rac and Cdc42) (Just et al., 1995). This glucosylation leads to functional inactivation. As Rho GTPases regulate the dynamics of the actin cytoskeleton (Hall, 1998), their inactivation leads to a reorganization of filamentous actin structures. Thus, the predominant effect of $\mathrm{TcdA}$ and $\mathrm{TcdB}$ is the breakdown of the actin cytoskeleton, accompanied by a change in cell morphology. Rho GTPase inhibition results in inhibition of migration, morphogenesis, cell division (Jaffe \& Hall, 2005) and membrane trafficking (Ridley, 2001). Additionally, Rho GTPases are involved in transcriptional regulation and apoptosis (Aznar \& Lacal, 2001; Symons, 1996). They play a critical role in apoptosis associated with

Abbreviation: FACS, fluorescence-activated cell sorting. morphological changes in cells (Coleman \& Olson, 2002; Coniglio et al., 2001), or contribute in a pro- or antiapoptotic manner as a response to genotoxic stress (Fritz \& Kaina, 2006).

The apoptotic properties of $\mathrm{TcdA}$ and $\mathrm{TcdB}$ are well known. These toxins induce apoptosis in intestinal epithelial cells (Brito et al., 2002, 2005; Carneiro et al., 2006; Fiorentini et al., 1998; Liu et al., 2003; Mahida et al., 1998) and in all other cells tested such as neurons (Le et al., 2005), endothelial cells (Hippenstiel et al., 2002), HeLa cells (Qa'Dan et al., 2002) and monocytes (Warny \& Kelly, 1999). It is common sense that the executioner caspase-3 is involved in TcdA-induced apoptosis (Brito et al., 2002; Carneiro et al., 2006; Hippenstiel et al., 2002; Le et al., 2005; Qa'Dan et al., 2002; Solomon et al., 2005). Additionally, activation of caspase-6, another executioner caspase, can also be observed (Brito et al., 2002; Carneiro et al., 2006). The initiator caspase- 8 represents the extrinsic apoptotic pathway, which can be activated via transmembrane death receptors such as the Fas receptor. Caspase-9, representing the intrinsic pathway, is activated by an 
apoptosome containing cytochrome $c$ released from damaged mitochondria (Boatright \& Salvesen, 2003). Both initiator caspases ( 8 and 9) are known to cleave procaspase- 3 into the activated caspase- 3 . The activation of the intrinsic pathway by clostridial toxins has been described by different authors. Cytochrome $c$ is released from mitochondria in response to treatment with TcdA or TcdB (Brito et al., 2002; Gerhard et al., 2005; Kim et al., 2005; Le et al., 2005; Liu et al., 2003). As a consequence, caspase-9 is consecutively activated (Brito et al., 2002; Carneiro et al., 2006; Hippenstiel et al., 2002; Le et al., 2005; Liu et al., 2003). However, caspase- 8 also plays a role in TcdA-induced apoptosis (Brito et al., 2002; Carneiro et al., 2006). Intracellular effects of TcdA that trigger proapoptotic events are not known. The glucosylation of Rho GTPases as a prerequisite for apoptosis is controversial and is discussed below. Mutant forms of TcdA (Teichert et al., 2006) were used here to elucidate the impact of Rho glucosylation on the apoptotic processes.

\section{METHODS}

Chemicals and reagents. The antibodies used were: polyclonal anti-caspase- 3 antibody recognizing procaspase- 3 and cleaved caspase-3, polyclonal antibody recognising cleaved caspase-8 (Asp374) and polyclonal antibody recognising cleaved caspase-9 (Asp315) (all from Acris Antibodies), monoclonal anti-Racl antibody (clone 102; BD PharMingen), monoclonal anti-Racl antibody (clone 23A8; Upstate), horseradish-conjugated anti-mouse IgG and anti-rabbit IgG (Rockland Immunochemicals). The pan-caspase inhibitor $\mathrm{z}$ VAD-fmk was from Merck Biosciences. The Bacillus megaterium expression system was from MoBiTec.

Cell culture. The colonic crypt cell line HT-29 was cultured under standard conditions in Dulbeccos' modified Eagle's medium/F12 mix supplemented with $10 \%$ fetal bovine serum, $100 \mu \mathrm{M}$ penicillin and $100 \mu \mathrm{g}$ streptomycin $\mathrm{ml}^{-1}$. For stimulation experiments, cells were seeded in Petri dishes $(3.5 \mathrm{~cm}$ diameter) coated with fibronectin.

Preparation of toxins. All experiments were performed with expressed recombinant TcdA. The recombinant and genetically engineered mutants were expressed in a $B$. megaterium expression system as His-tagged fusion proteins. The constructs were sequenced to ensure that the sequence was identical compared with the reference gene of C. difficile TcdA, strain VPI 10463 (GenBank accession no. X51797), except for the desired mutations. Purification was performed by $\mathrm{Ni}^{2+}$ affinity chromatography as described previously (Burger et al., 2003). Toxins were stored until use in $10 \mathrm{mM}$ Tris/ $\mathrm{HCl}$ ( $\mathrm{pH} 7.4), 50 \mathrm{mM} \mathrm{NaCl}$ at $-80{ }^{\circ} \mathrm{C}$. The recombinant toxins exhibited all features of the native TcdA, i.e. glucosyltransferase activity (except when specifically reduced by directed mutagenesis), cell binding, endocytotic uptake and autocatalytic cleavage of the catalytic domain (data not shown). Different conditions for expression and purification of native TcdA from C. difficile and of the recombinant TcdA did not induce alteration of any of these features (Gerhard et al., 2005). The absence of cytotoxic impurities acting on isolated mitochondria was checked using a cytochrome $c$ release assay.

Flow cytometry. The number of apoptotic or necrotic cells was counted by fluorescence-activated cell sorting (FACS). Detached and adherent cells, which were suspended by trypsinization, were pooled before FACS analysis. The DNA content was measured using the fluorescent nucleotide acid dye propidium iodide. Cells $\left(0.5 \times 10^{6}\right)$ were fixed in $70 \%$ ice-cold ethanol for $30 \mathrm{~min}$ and washed once with $1 \%$ BSA in PBS. The DNA was stained with propidium iodide $\left[150 \mu \mathrm{g} \mathrm{ml}^{-1}\right.$ in Tris/HCl (pH 7.4) containing $1 \%$ BSA and $1 \%$ Triton X-100]. RNA was removed by incubating the cells with $0.5 \%$ RNase for $30 \mathrm{~min}$. The cells were then subjected to flow cytometry (FACScan flow cytometer; Becton Dickinson). A fluorescence area (FL2) of 400 was set to correlate with a $2 n$ set of chromosomes within the $G_{1}$ phase. Cells found in the sub- $G_{1}$ phase were considered to be apoptotic and necrotic due to the decrease in DNA content.

Western blotting. Activation of caspase- $9,-8$, and -3 was shown by Western blot analysis, using antibodies that recognize the cleaved and thus activated caspases. Whole-cell homogenates were resolved by SDS-PAGE and transferred to nitrocellulose. Immunodetection was performed in Tris-buffered saline containing $0.2 \%(\mathrm{v} / \mathrm{v})$ Tween 20. The nitrocellulose was incubated overnight at $4{ }^{\circ} \mathrm{C}$ with primary antibodies, followed by the appropriate secondary antibody for $45 \mathrm{~min}$ at room temperature. Femto SuperSignal ECL Substrate (Pierce) was used for detection.

Statistical analysis. A two-sided Student's $t$-test was performed to determine significant effects. A value of $P<0.01$ was considered significant and is indicated with asterisks in the figures. The $t$-test was only used for studies with $n \geqslant 5$ experiments. All values are given as means \pm SD.

\section{RESULTS AND DISCUSSION}

All experiments were performed using expressed recombinant TcdA. The recombinant toxins exhibited all features of the native TcdA, i.e. glucosyltransferase activity (except when specifically reduced by directed mutagenesis), cell binding, endocytotic uptake and autocatalytic cleavage of the catalytic domain (data not shown). Different conditions for expression and purification of native TcdA from C. difficile and of the recombinant TcdA did not induce alteration of any of these features (Gerhard et al., 2005).

\section{Glucosyltransferase activity of TcdA is crucial for induction of apoptosis}

TcdA ( $3 \mathrm{nM}$ ) induced morphological changes in HT-29 cells and the cells rounded up within $8 \mathrm{~h}$ (Fig. 1a). The kinetics of Rac glucosylation, which was assayed using a specific antibody (Genth et al., 2006), was in strong correlation with cell rounding (data not shown). The activation of caspase- 3 followed the glucosylation of Rho GTPases. The results of Western blot analyses with specific antibody recognizing uncleaved procaspase- $3(35 \mathrm{kDa})$ as well as the cleaved and thus activated caspase-3 $(12 \mathrm{kDa})$ are shown in Fig. 1(b). There was a strong correlation between caspase activation (Fig. 1b, upper panel) and Rac1 glucosylation (Fig. 1b, middle panel). Total Racl is shown in the lower panel. The maximum activation of caspase- 3 was detectable only when Racl was quantitatively glucosylated. The $50 \%$ effective concentration required to activate caspase- 3 after $36 \mathrm{~h}$ was approximately $50 \mathrm{ng}$ TcdA ml ${ }^{-1}(0.2 \mathrm{nM})$. Recombinant TcdA with mutations that specifically affect the glucosyltransferase activity (Fig. 2a) is an ideal tool to distinguish between glucosyltransferase-dependent and -independent effects. Different mutants 
(a)

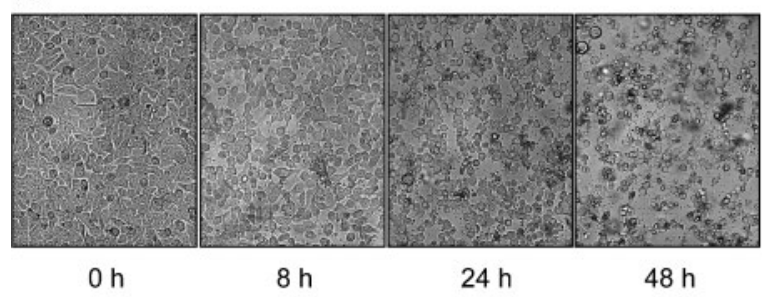

(b)

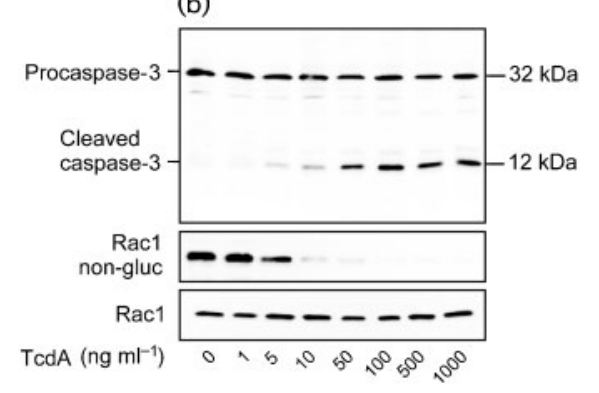

Fig. 1. (a) Morphological changes in HT-29 cells treated with TcdA for the indicated times. (b) Western blot analysis showing activation of caspase- 3 after $36 \mathrm{~h}$ of treatment with TcdA at the indicated concentrations. The $50 \%$ effective concentration of caspase- 3 was determined by treatment with $50 \mathrm{ng} \mathrm{TcdA} \mathrm{ml}{ }^{-1}$ (upper panel). Glucosylation of Rac1 was detected by Western blot analysis with a specific antibody that specifically recognizes non-glucosylated Rac1 (middle panel) and total Rac1 (lower panel). The blots shown are representative of at least three separate experiments.

were used to check for glucosyltransferase-independent effects. The purity of toxin preparation (Fig. 2b, left panel) and the absence of cleaved N-terminal glucosyltransferase (Fig. 2b, right panel) were checked by SDS-PAGE and Western blot analysis with specific anti-TcdA1-542 antibody, respectively. TcdA W101A had 50-fold reduced glucosyltransferase activity compared with wild-type TcdA, and was applied in an equimolar or equipotent ratio to distinguish between Rho glucosylating effects and those that are independent. The double mutant TcdA D285/ $287 \mathrm{~N}$ does not glucosylate Rho GTPases when applied to cells, even at the highest achievable concentration of $0.3 \mu \mathrm{M}$ (Teichert et al., 2006). The cytotoxic effect of TcdA resulting from caspase activation was measured by flow cytometry. As shown in Fig. 2(c), $1 \mathrm{nM}$ TcdA induced apoptosis in $28 \pm 6 \%$ of cells after $36 \mathrm{~h}$ incubation compared with untreated cells $(5 \pm 2 \%)$. The double mutant TcdA D285/287N, which had no Rho glucosylating properties in a cell culture assay, did not induce apoptosis $(4 \pm 3 \%)$. Mutant TcdA W101A led to a slight and nonsignificant increase $(8 \pm 4 \%)$ in the number of apoptotic cells at a concentration of $1 \mathrm{nM}$. However, at a 50 -fold concentration, TcdA W101A had similar apoptotic features $(21 \pm 15 \%)$ to wild-type TcdA. Thus, the apoptotic effect of TcdA correlates with the glucosyltransferase activity that (a)

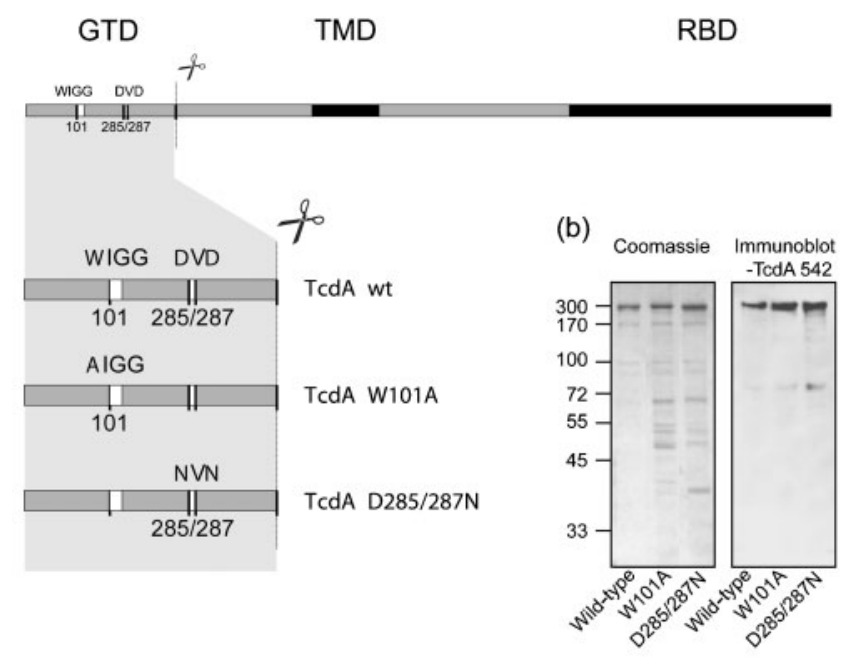

(c)

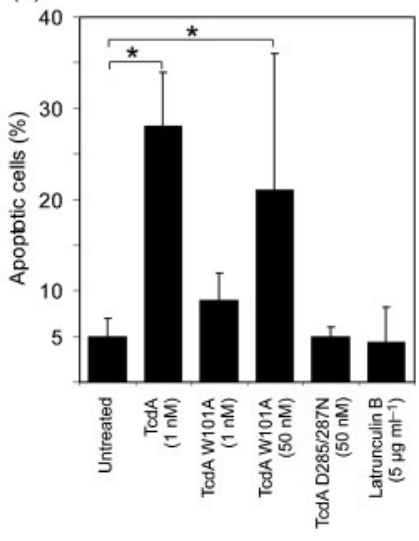

(d)

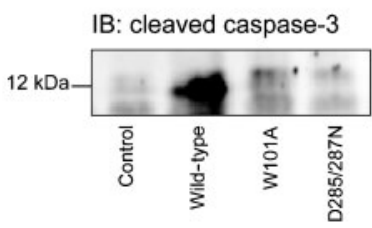

Fig. 2. (a) Structure of TcdA. The N-terminal glucosyltransferase domain (GTD) consisting of aa 1-542 is cleaved intracellularly by an autoproteolytic cleavage. The transmembrane domain (TMD) and the receptor-binding domain (RBD) facilitate binding to the target cell and translocation of the GTD into the cytosol. Two conserved motifs within the GTD participate in binding of the cosubstrate UDP-glucose. Mutation of the tryptophan within the WIGG motif (W101A) results in a 50-fold reduction in glucosyltransferase activity. TcdA D285/287N is a double mutant where the DXD motif was altered to extinguish the glucosyltransferase activity. (b) Left panel: Coomassie gel showing the purity of the toxin preparation. Right panel: Western blot analysis using an antibody specific for the N-terminal fragment of TcdA (aa 1-542) showing that preparations did not contain cleaved glucosyltransferase domain. (c) Apoptosis of cells treated with TcdA and mutant TcdA, estimated by flow cytometry. Wild-type TcdA (1 nM), TcdA $\mathrm{W} 101 \mathrm{~A}$ at an equipotent $(50 \mathrm{nM})$ or equimolar concentration $(1 \mathrm{nM}), \operatorname{TcdA} \mathrm{D} 285 / 287 \mathrm{~N}(50 \mathrm{nM})$ or latrunculin $\mathrm{B}\left(5 \mu \mathrm{g} \mathrm{ml}^{-1}\right)$ were applied to investigate glucosyltransferase-independent apoptotic effects. The results shown are means \pm SD $(n=5)$. *, $P<0.01$. (d) Western blot analysis showing cleaved caspase- 3 of HT-29 cells after $36 \mathrm{~h}$ treatment with wild-type TcdA, TcdA W101A or TcdA D285/287N (1 nM each). 
is displayed intracellularly. Destruction of the actin cytoskeleton alone by latrunculin B $\left(5 \mu \mathrm{g} \mathrm{ml}^{-1}\right)$ did not induce apoptosis in HT-29 cells. Fig. 2(d) shows the activated, i.e. cleaved, caspase-3 after treatment of cells with either wild-type TcdA, TcdA W101A or TcdA D285/ $287 \mathrm{~N}$ ( $1 \mathrm{nM}$ each). This set of experiments showed that apoptosis was induced only when Rho GTPases were maximally glucosylated (compare with Fig. 1b). Breakdown of the actin cytoskeleton was a sequel of Rho glucosylation, but did not cause apoptosis.

Cells treated with TcdA $(1 \mathrm{nM})$ arrested at the $\mathrm{G}_{2} / \mathrm{M}$ transition as a sequel to the breakdown of the actin cytoskeleton (Fig. 3). After $12 \mathrm{~h}$, about $17 \%$ of cells were found in this phase. At $24 \mathrm{~h}$, the cells started to become apoptotic with a maximum of $42 \%$ of cells after $48 \mathrm{~h}$. However, an arrest within the $\mathrm{G}_{2} / \mathrm{M}$ transition did not necessarily induce apoptosis, as could be seen by the latrunculin B experiment. Latrunculin B induced arrest within the $\mathrm{G}_{2} / \mathrm{M}$ phase in $14 \%$ of cells without increasing the number of apoptotic cells.

\section{TcdA-induced apoptosis depends on the activation of caspases}

HT-29 cells were subjected to flow cytometry to measure DNA content. Cells with a DNA content less than that of cells with a $2 n$ set of chromosomes ( $G_{1}$ phase) were considered apoptotic. Fig. 4(a) shows representative FACS data of untreated HT-29 cells and cells treated with $1 \mathrm{nM}$ TcdA in the presence or absence of the pan-caspase inhibitor z-VAD-fmk $(50 \mu \mathrm{M})$. The caspase inhibitor fully prevented the apoptotic outcome of TcdA treatment, as

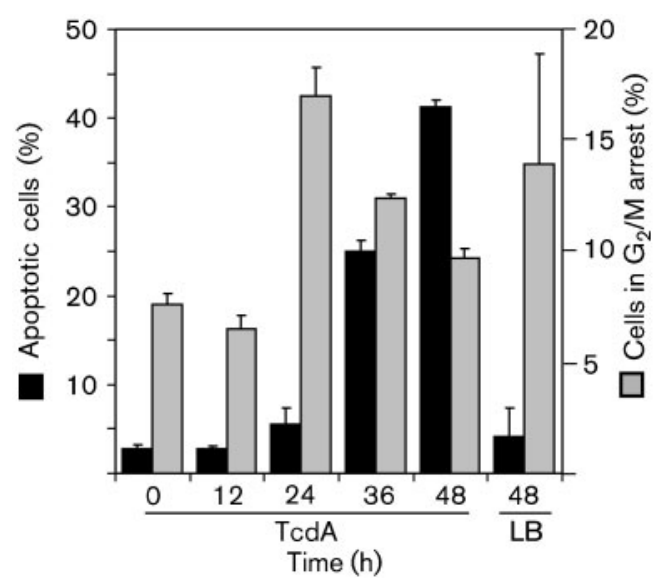

Fig. 3. Time-dependent effect of $T c d A$ on $G_{2} / M$ arrest and apoptosis. The number of apoptotic cells (black bars) and cells that arrested within the $\mathrm{G}_{2} / \mathrm{M}$ transition (grey bars) are shown, as determined by flow cytometry. Cells were treated with $\mathrm{Tcd} A$ $(1 \mathrm{nM})$ for the indicated times. Latrunculin B (LB) $\left(5 \mu \mathrm{g} \mathrm{ml}^{-1}\right)$ was applied for $48 \mathrm{~h}$ as a control for cytoskeleton-induced $\mathrm{G}_{2} / \mathrm{M}$ arrest. The results are shown are means $\pm \mathrm{SD}(n=5)$. (a)

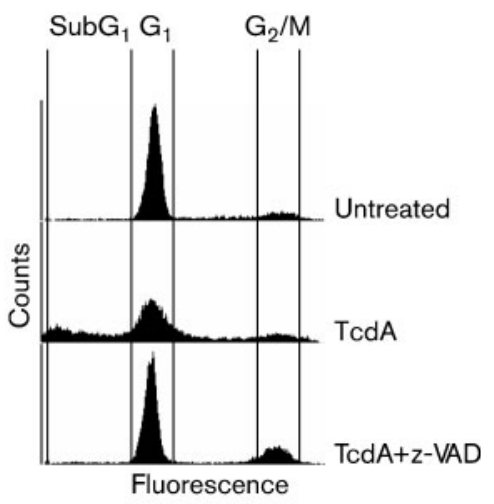

(b)

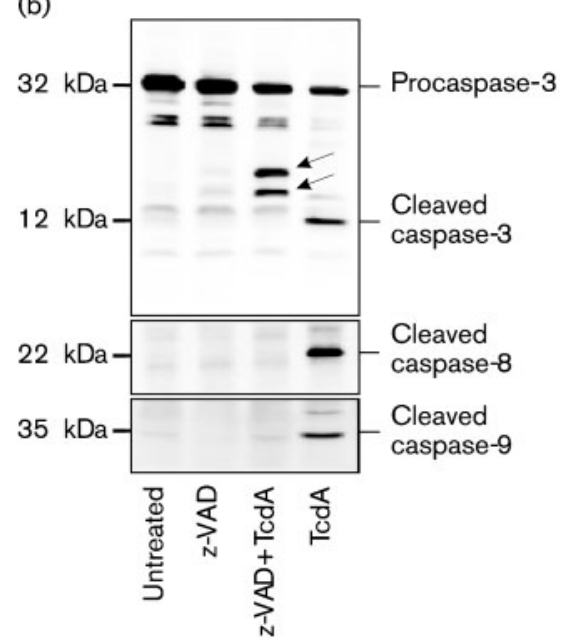

Fig. 4. (a) Flow cytometry data from cells treated with $T c d A$ $(1 \mathrm{nM})$ in the presence or absence of $50 \mu \mathrm{M} z$-VAD-fmk (pancaspase inhibitor). Cells with a DNA content less than cells within the $G_{1}$ phase (sub- $G_{1}$ ) were considered apoptotic. (b) Western blot of caspase-3, -8 and -9 . The pan-caspase inhibitor abolished cleavage of caspase- 8 and -9 , but did not prevent cleavage of procaspase- 3 into intermediate fragments (indicated by arrows).

could be seen by a decrease in the number of cells within the sub- $G_{1}$ phase. The ability of TcdA to arrest cells within the $G_{2} / M$ transition was observed when cells were not allowed to become apoptotic. Compared with untreated cells, TcdA induced a strong cell-cycle arrest in the $\mathrm{G}_{2} / \mathrm{M}$ phase when apoptosis was blocked by z-VAD-fmk. Thus, there was no caspase-independent cell death of TcdAtreated cells.

\section{Caspase-3 plays a central role in TcdA-induced apoptosis}

Apoptosis induced by TcdA can be abolished by blocking caspase activity. The hierarchy of caspases involved in TcdA-induced apoptosis is not known so far. We applied the pan-caspase inhibitor z-VAD-fmk $(50 \mu \mathrm{M})$ to check which caspase is the primary one that is cleaved by a non- 
caspase protease, and which caspases are downstream of other caspases. Treatment of cells with TcdA led to cleavage of procaspase-3. Western blot analysis showed a reduced specific signal for procaspase- 3 and an increase in the $12 \mathrm{kDa}$ fragment of the active caspase-3 (Fig. 4b, upper panel). Surprisingly, procaspase-3, the precursor of the executioner caspase-3, was cleaved, even in the presence of z-VAD-fmk. Compared with controls, there was less procaspase- 3 and, in addition, two intermediate fragments of 20 and $17 \mathrm{kDa}$ were generated. The signals can be interpreted as follows: firstly, cleavage of procaspase-3 was performed by a non-caspase protease and further autocleavage resulting in the $12 \mathrm{kDa}$ fragment was inhibited by z-VAD-fmk. Cleavage of procaspase- 8 and procaspase- 9 was completely inhibited by $\mathrm{z}$-VAD-fmk, indicating that these caspases are activated by an upstream caspase (Fig. $4 \mathrm{~b}$, middle and lower panels, respectively).

TcdA induced activation of caspase-3, -8 and -9 in HT-29 cells and thereby triggered apoptotic cell death. Activation of the executioner caspase-3 strongly correlated with the glucosylation of Rac1. Significant cleavage of procaspase- 3 was detected when TcdA was applied at concentrations that were sufficient to achieve quantitative glucosylation of the Racl pool. It is not known which GTPase is the crucial one for induction of activation of caspases when glucosylated. The kinetics of TcdA-catalysed Rac and Rho glucosylation are almost identical (Teichert et al., 2006), and thus Western blot analysis of non-glucosylated Racl is an ideal surrogate for the intracellular action of TcdA (Genth et al., 2006). The correlation of the extent of glucosylation of Rho GTPases and the increasing activation of caspase- 3 strongly suggest that inhibition of Rho GTPases is a cause of apoptotic cell death. A single report has described the Rho-independent effect of TcdA (Kim et al., 2005), and it is likely that TcdA exhibits functions additional to its glucosyltransferase activity when applied to cells. To study the effect of glucosylation events in TcdA-induced cell death, we used a set of TcdA mutants that differed solely in their glucosyltransferase activity. These experiments clearly showed that apoptotic cell death strictly depended on the glucosyltransferase activity of these toxins in our model system. No effect on caspases or cell viability was observed when TcdA W101A (with reduced glucosyltransferase activity) or TcdA D285/ $287 \mathrm{~N}$ (no glucosyltransferase activity) was applied at concentrations higher than that of wild-type TcdA sufficient to induce maximum effects. It is not known whether inhibition of Rho, Rac, Cdc42 or a combination of these GTPases is responsible for the TcdA-induced apoptosis. Rho GTPases are positively involved in transduction of receptormediated apoptotic signals (Brenner et al., 1997), and can also be negatively involved (Esteve et al., 1998; Rattan et al., 2006). Inhibition of Rho by exoenzyme C3-catalysed ADP ribosylation (Bobak et al., 1997; Ikeda et al., 2003; Li et al., 2002), as well as dominant-negative Rac1 and Cdc42 mutants, induces apoptosis (Lassus et al., 2000). Specific glucosylation of Rac/Cdc42 by lethal toxin from Clostridium sordellii also induces apoptosis (Linseman et al., 2001; Petit et al., 2003). The predominance of either these Rho GTPases may be the reason for the different sensitivities, and indicates the difficulties in estimating the relative contribution of these Rho GTPases to the apoptotic properties of Rhoglucosylating toxins.

Caspase- 3 is the central player in TcdA-induced cell death. Inhibition of the executioner caspase- 3 prevented an apoptotic outcome for cells treated with TcdA for at least $48 \mathrm{~h}$. The most important finding was that the first cleavage of procaspase- 3 into intermediate fragments was carried out by a protease that was not susceptible to a pancaspase inhibitor. This indicates that a non-caspase protease triggers activation of the cascade of caspases, where caspase-3 is simultaneously the initiator and executioner caspase. Caspase- 8 and -9 are also involved, but seem to participate only in an amplifying manner.

The results of this study are summarized in a schematic diagram (Fig. 5). Treatment of cells with TcdA causes inhibition of Rho GTPases. This causes a reorganization of the actin cytoskeleton, which in turn results in arrest at the $\mathrm{G}_{2} / \mathrm{M}$ transition. This effect is referred to as the cytopathic effect. Glucosylation of Rho GTPases also causes activation of caspases, which is independent of the effect on the actin cytoskeleton. Active caspase-3 induces apoptosis, i.e. the cytotoxic effect of TcdA. By application of different mutants of TcdA, we have shown that the glucosyltransferase activity of TcdA is responsible for both the cytopathic and the cytotoxic effect.

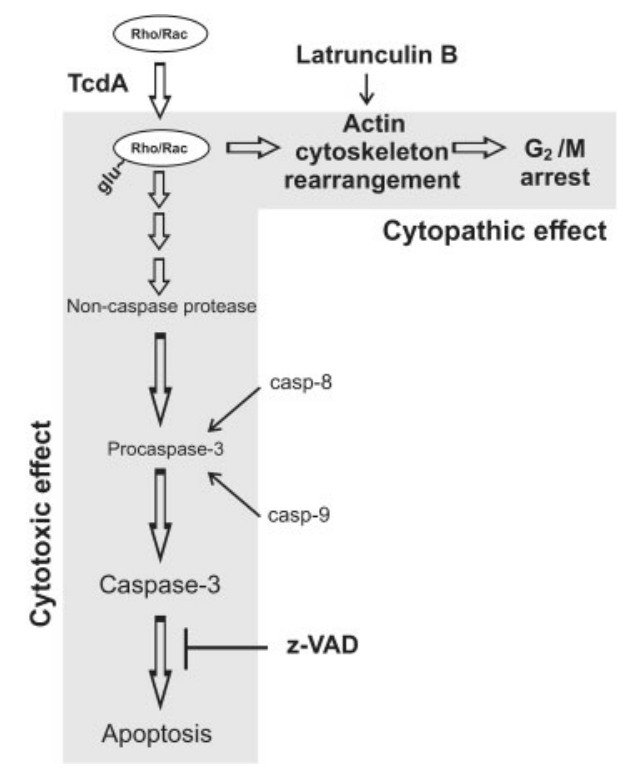

Fig. 5. Schematic diagram of the cytopathic and cytotoxic effects of TcdA. Glucosylation of Rho GTPases induces reorganization of the actin cytoskeleton with subsequent $G_{2} / M$ arrest (cytopathic effect). Independently of the cytoskeleton, Rho glucosylation results in activation of caspase- 3 to execute apoptosis (cytotoxic effect). Caspase- 8 and -9 participate in an amplifying manner. 


\section{REFERENCES}

Aznar, S. \& Lacal, J. C. (2001). Rho signals to cell growth and apoptosis. Cancer Lett 165, 1-10.

Boatright, K. M. \& Salvesen, G. S. (2003). Mechanisms of caspase activation. Curr Opin Cell Biol 15, 725-731.

Bobak, D., Moorman, J., Guanzon, A., Gilmer, L. \& Hahn, C. (1997). Inactivation of the small GTPase Rho disrupts cellular attachment and induces adhesion-dependent and adhesion-independent apoptosis. Oncogene 15, 2179-2189.

Brenner, B., Koppenhoefer, U., Weinstock, C., Linderkamp, O., Lang, F. \& Gulbins, E. (1997). Fas- or ceramide-induced apoptosis is mediated by a Rac1-regulated activation of Jun N-terminal kinase/p38 kinases and GADD153. J Biol Chem 272, 22173-22181.

Brito, G. A. C., Fujji, J., Carneiro, B. A., Lima, A. A. M., Obrig, T. \& Guerrant, R. L. (2002). Mechanism of Clostridum difficile toxin Ainduced apoptosis in T84 cells. J Infect Dis 186, 1438-1447.

Brito, G. A., Carneiro-Filho, B., Oria, R. B., Destura, R. V., Lima, A. A. \& Guerrant, R. L. (2005). Clostridium difficile toxin A induces intestinal epithelial cell apoptosis and damage: role of Gln and AlaGln in toxin A effects. Dig Dis Sci 50, 1271-1278.

Burger, S., Tatge, H., Hofmann, F., Just, I. \& Gerhard, R. (2003). Expression of recombinant Clostridium difficile toxin A using the Bacillus megaterium system. Biochem Biophys Res Commun 307, 584588.

Carneiro, B. A., Fujii, J., Brito, G. A., Alcantara, C., Oria, R. B., Lima, A. A., Obrig, T. \& Guerrant, R. L. (2006). Caspase and Bid involvement in Clostridium difficile toxin A-induced apoptosis and modulation of toxin A effects by glutamine and alanyl-glutamine in vivo and in vitro. Infect Immun 74, 81-87.

Coleman, M. L. \& Olson, M. F. (2002). Rho GTPase signalling pathways in the morphological changes associated with apoptosis. Cell Death Differ 9, 493-504.

Coniglio, S. J., Jou, T. S. \& Symons, M. (2001). Rac1 protects epithelial cells against anoikis. J Biol Chem 276, 28113-28120.

Esteve, P., Embade, N., Perona, R., Jimenez, B., del Peso, L., Leon, J., Arends, M., Miki, T. \& Lacal, J. C. (1998). Rho-regulated signals induce apoptosis in vitro and in vivo by a p53-independent, but $\mathrm{Bcl} 2$ dependent pathway. Oncogene 17, 1855-1869.

Fiorentini, C., Fabbri, A., Falzano, L., Fattorossi, A., Matarrese, P., Rivabene, R. \& Donelli, G. (1998). Clostridium difficile toxin B induces apoptosis in intestinal cultured cells. Infect Immun 66, 2660-2665.

Fritz, G. \& Kaina, B. (2006). Rho GTPases: promising cellular targets for novel anticancer drugs. Curr Cancer Drug Targets 6, 1-14.

Genth, H., Huelsenbeck, J., Hartmann, B., Hofmann, F., Just, I. \& Gerhard, R. (2006). Cellular stability of Rho-GTPases glucosylated by Clostridium difficile toxin B. FEBS Lett 580, 3565-3569.

Gerhard, R., Burger, S., Tatge, H., Genth, H., Just, I. \& Hofmann, F. (2005). Comparison of wild type with recombinant Clostridium difficile toxin A. Microb Pathog 38, 77-83.

Hall, A. (1998). Rho GTPases and the actin cytoskeleton. Science 279, 509-514.

Hippenstiel, S., Schmeck, B., N'Guessan, P. D., Seybold, J., Krüll, M., Preissner, K., Von Eichel-Streiber, C. \& Suttorp, N. (2002). Rho protein inactivation induced apoptosis of cultured human endothelial cells. Am J Physiol Lung Cell Mol Physiol 283, L830-L838.

Ikeda, H., Nagashima, K., Yanase, M., Tomiya, T., Arai, M., Inoue, Y., Tejima, K., Nishikawa, T., Omata, M. \& other authors (2003). Involvement of Rho/Rho kinase pathway in regulation of apoptosis in rat hepatic stellate cells. Am J Physiol Gastrointest Liver Physiol 285, G880-G886.
Jaffe, A. B. \& Hall, A. (2005). Rho GTPases: biochemistry and biology. Annu Rev Cell Dev Biol 21, 247-269.

Just, I. \& Gerhard, R. (2004). Large clostridial cytotoxins. Rev Physiol Biochem Pharmacol 152, 23-47.

Just, I., Selzer, J., Wilm, M., Von Eichel-Streiber, C., Mann, M. \& Aktories, K. (1995). Glucosylation of Rho proteins by Clostridium difficile toxin B. Nature 375, 500-503.

Kim, H., Kokkotou, E., Na, X., Rhee, S. H., Moyer, M. P., Pothoulakis, C. \& LaMont, J. T. (2005). Clostridium difficile toxin A-induced colonocyte apoptosis involves p53-dependent p21(WAF1/CIP1) induction via p38 mitogen-activated protein kinase. Gastroenterology 129, 1875-1888.

Lassus, P., Roux, P., Zugasti, O., Philips, A., Fort, P. \& Hibner, U. (2000). Extinction of Racl and Cdc42Hs signalling defines a novel p53-dependent apoptotic pathway. Oncogene 19, 2377-2385.

Le, S. S., Loucks, F. A., Udo, H., Richardson-Burns, S., Phelps, R. A., Bouchard, R. J., Barth, H., Aktories, K., Tyler, K. L. \& other authors (2005). Inhibition of Rac GTPase triggers a c-Jun and Bim-dependent mitochondrial apoptotic cascade in cerebellar granule neurons. $J$ Neurochem 94, 1025-1039.

Li, X., Liu, L., Tupper, J. C., Bannerman, D. D., Winn, R. K., Sebti, S. M., Hamilton, A. D. \& Harlan, J. M. (2002). Inhibition of protein geranylgeranylation and RhoA/RhoA kinase pathway induces apoptosis in human endothelial cells. J Biol Chem 277, 15309-15316.

Linseman, D. A., Laessig, T., Meintzer, M. K., McClure, M., Barth, H. Aktories, K. \& Heidenreich, K. A. (2001). An essential role for Rac/ Cdc42 GTPases in cerebellar granule neuron survival. J Biol Chem 276, 39123-39131.

Liu, T. S., Musch, M. W., Sugi, K., Walsh-Reitz, M. M., Ropeleski, M. J., Hendrickson, B. A., Pothoulakis, C., LaMont, J. T. \& Chang, E. B. (2003). Protective role of HSP72 against Clostridium difficile toxin Ainduced intestinal epithelial cell dysfunction. Am J Physiol Cell Physiol 284, C1073-C1082.

Mahida, Y. R., Galvin, A., Makh, S., Hyde, S., Sanfilippo, L., Borriello, S. P. \& Sewell, J. L. (1998). Effect of Clostridium difficile toxin A on human colonic lamina propria cells: early loss of macrophages followed by T-cell apoptosis. Infect Immun 66, 5462-5469.

Petit, P., Bréard, J., Montalescot, V., El Hadj, N. B., Levade, T., Popoff, M. \& Geny, B. (2003). Lethal toxin from Clostridium sordellii induces apoptotic cell death by disruption of mitochondrial homeostasis in HL-60 cells. Cell Microbiol 5, 761-771.

Qa'Dan, M., Ramsey, M., Daniel, J., Spyres, L. M., Safiejko-Mroczka, B., Ortiz-Leduc, W. \& Ballard, J. D. (2002). Clostridium difficile toxin B activates dual caspase-dependent and caspase-independent apoptosis in intoxicated cells. Cell Microbiol 4, 425-434.

Rattan, R., Giri, S., Singh, A. K. \& Singh, I. (2006). Rho/ROCK pathway as a target of tumor therapy. J Neurosci Res 83, 243-255.

Ridley, A. J. (2001). Rho proteins: linking signaling with membrane trafficking. Traffic 2, 303-310.

Solomon, K., Webb, J., Ali, N., Robins, R. A. \& Mahida, Y. R. (2005). Monocytes are highly sensitive to Clostridium difficile toxin Ainduced apoptotic and nonapoptotic cell death. Infect Immun 73, $1625-1634$.

Symons, M. (1996). Rho family GTPases: the cytoskeleton and beyond. Trends Biochem Sci 21, 178-181.

Teichert, M., Tatge, H., Schoentaube, J., Just, I. \& Gerhard, R. (2006). Application of mutated Clostridium difficile Toxin A for determination of glucosyltransferase-dependent effects. Infect Immun 74, 6006-6010.

Warny, M. \& Kelly, C. P. (1999). Monocytic cell necrosis is mediated by potassium depletion and caspase-like proteases. Am J Physiol 276, C717-C724. 